\title{
Expression of TLR4 gene is downregulated in acquired immune deficiency syndrome-associated Kaposi's sarcoma
}

\author{
XIAOBO LU ${ }^{1}$, XUEFENG WAN ${ }^{2}$, XIAORAN LI $^{1}$, KEJUN PAN $^{1}$, WUBULI MAIMAITIAILI $^{1}$ and YUEXIN ZHANG $^{1}$ \\ Departments of ${ }^{1}$ Infectious Diseases and ${ }^{2}$ Dermatology, The First Affiliated Hospital of Xinjiang Medical University, \\ Urumqi, Xinjiang 830054, P.R. China
}

Received July 15, 2016; Accepted December 12, 2017

DOI: $10.3892 /$ etm.2018.6941

\begin{abstract}
The present study investigated the expression of Toll-like receptor 4 (TLR4) and proteins involved in its associated signaling pathways in patients with classic Kaposi's sarcoma (KS) and acquired immune deficiency syndrome (AIDS)-associated KS (AIDS-KS) in Xinjiang Autonomous Region of China. A total of 35 patients with KS were enrolled in the present study between May 2011 and July 2013, including 26 cases of AIDS-KS and 9 cases of classic KS. Another 10 healthy subjects of the Uygur ethnic group were included in the normal control group. KS tissues were subjected to hematoxylin and eosin staining and immunohistochemical staining. To measure the expression of mRNA, reverse-transcription quantitative polymerase chain reaction was performed. To determine protein expression, western blot analysis was employed. AIDS-KS was mainly distributed in the face and limbs, while classic KS was mainly distributed in the limbs. The histopathological characteristics of AIDS-KS and classic KS tissues were different from those of normal tissues. TLR4 was mainly distributed in the dermis of KS tissues. The mRNA expression levels of TLR4 were reduced in classic KS and AIDS-KS. The protein expression levels of RAS, RAF, nuclear factor (NF) $-\kappa B$ P65 and P50 as well as inhibitor of NF- $\kappa$ B- $\alpha$ of the TLR4 signaling pathway in AIDS-KS and KS tissues were higher than those in normal tissues. In conclusion, the expression of TLR4 gene in KS tissues was decreased, while the expression of proteins of the TLR4 signaling pathway was upregulated in KS. Downregulation of TLR4 may be associated with the occurrence and development of AIDS-KS, while its restoration may represent a novel therapeutic approach for AIDS-KS.
\end{abstract}

Correspondence to: Dr Wubuli Maimaitiaili, Department of Infectious Diseases, The First Affiliated Hospital of Xinjiang Medical University, 137 South Liyushan Road, Urumqi, Xinjiang 830054, P.R. China

E-mail: 15899199151@163.com

Key words: toll-like receptor 4, Kaposi's sarcoma, acquired immune deficiency syndrome

\section{Introduction}

Kaposi's sarcoma (KS) is a vascular malignant tumor type that is characterized by abnormal angiogenesis and inflammation. KS usually occurs in the skin of the face and may affect viscera, mucosa, the lungs and oral cavity (1). Xinjiang Autonomous Region in China is a region with high morbidity of KS and acquired immune deficiency syndrome (AIDS)-associated Kaposi's sarcoma (AIDS-KS) and the disease is most commonly seen in the Uygur and Kazakh ethnic groups (2). However, KS is rarely found in other regions or ethnic groups in China. Toll-like receptor 4 (TLR4) is a recognition receptor of lipopolysaccharide that participates in the recognition process of protein components in viruses. It is mainly expressed in immune cells, such as macrophages, $\mathrm{T}$ cells, B lymphocytes and endothelial cells. Activation of TLR4 induces a series of inflammatory mediators, including cytokines and chemokines, to produce a strong inflammatory reaction. TLR4 has an important role in anti-bacterial, inflammatory, anti-viral and stress processes. TLR4 recognizes pathogen-associated molecular patterns. It participates in innate immune responses via the activation of cell signaling pathways that lead to the transcription of pro-inflammatory cytokine genes, such as interleukin (IL)-12, IL-6, tumor necrosis factor- $\alpha$ and type I interferon (IFN). As a result, TLR4 is involved in the pathogenesis of various viral infections. TLR4 also has important roles in innate and adaptive immunity, such as KS-associated herpesvirus (KSHV) infection (3). However, the role and regulation of TLRs in innate immunity against AIDS-KS have remained elusive. The present study investigated the expression of TLR4 and its signaling proteins in classic KS and AIDS-KS.

\section{Materials and methods}

Patients. A total of 35 patients with $\mathrm{KS}$ were included in the present study between May 2011 and July 2013, including 26 cases of AIDS-KS and 9 cases of classic KS. All patients with KS were of Uygur ethnicity. Another 10 Uygur healthy subjects were included in the normal control group. The age and gender composition were not significantly different (P>0.05; Table I). Inclusion ecriteria for AIDS-KS were as follows: i) Uygur patients with HIV infection; ii) purple-brown plaque above the surface of the skin occurring on the face 
and verifiable by immunohistochemistry as KS; and iii) HIV infection confirmed by western blot analysis by Xinjiang Uygur Autonomous Region Center for Disease Control and Prevention. Exclusion criteria were as follows: i) Patients who suffer from sever skin diseases; ii) no definite diagnosis of KS; iii) patients with a history of mental illness or other circumstances due to which they did not cooperate with the experiment or sign the informed consent form. All procedures were approved by the Ethics Committee of Xinjiang Medical University. Written informed consent was obtained from all patients or their families.

Tissues. KS tissues were obtained from the patients during surgery, while skin tissues $(0.6 \times 0.3 \mathrm{~cm})$ were obtained from healthy subjects. After fixation with formaldehyde, the tissues were paraffin-embedded, followed by preparation of $5-\mu \mathrm{m}$ serial sections. The tissues underwent hematoxylin and eosin staining and immunohistochemical staining.

Hematoxylin and eosin staining. KS tissue samples were fixed, paraffin-embedded and cut into $5-\mu \mathrm{m}$ serial slices. The specimens were baked at $60^{\circ} \mathrm{C}$ over night and then de-paraffinized with xylene and re-hydrated, followed by washing under flowing water. Specimens were then placed in Harris-acidified hematoxylin for $2 \mathrm{~min}$, followed by a brief rinse in water. Slides were placed in eosin solution for $30 \mathrm{sec}$, followed by serial rinsing with ethanol and xylene, before coverslips were applied. The stained specimens were examined under a microscope (Olympus BX51, Tokyo, Japan).

Immunohistochemistry. Paraffin-embedded slices were de-waxed and de-hydrated according to standard procedures. The slices were treated with $3 \% \mathrm{H}_{2} \mathrm{O}_{2}$-methanol at room temperature to digest endogenous peroxidase. Bovine serum (10\%; Santa Cruz Biotechnology, Inc., Dallas, TX, USA) was used to block non-specific antibody binding. After removing the serum, TLR4 mouse anti-human monoclonal antibody (1:150 dilution; cat. no. sc-13593; Santa Cruz Biotechnology, Inc.) was added, followed by incubation at $4^{\circ} \mathrm{C}$ overnight. The samples were then incubated with horseradish peroxidase-conjugated rabbit anti-mouse monoclonal second antibody (1:1,000; cat. no. sc-516102; Santa Cruz Biotechnology, Inc.) at $37^{\circ} \mathrm{C}$ for $40 \mathrm{~min}$. The sections were developed using diaminobenzidine (Jinshan Reagent Company, Beijing, China) and counterstained using hematoxylin, followed by dehydration and mounting.

Reverse transcription-quantitative polymerase chain reaction $(R T-q P C R)$. Total RNA was extracted from ground tissues using TRIzol reagent (Thermo Fisher Scientific, Inc., Waltham, MA, USA). mRNA was reversely transcribed to complementary (c)DNA using a superscript III kit (Thermo Fisher Scientific, Inc.). First, RNA (10 $\mu \mathrm{l})$, Oligo-dT (1 $\mu \mathrm{l})$ and random primer $(1 \mu \mathrm{l})$ were mixed together prior to incubation at $65^{\circ} \mathrm{C}$ for $5 \mathrm{~min}$, followed by cooling on ice for $2 \mathrm{~min}$. Subsequently, $10 \mu \mathrm{M}$ deoxynucleotide triphosphate $(1 \mu \mathrm{l}), 0.1 \mathrm{M}$ dithiothreitol $(2 \mu \mathrm{l})$, $5 \mathrm{x}$ RT buffer $(4 \mu \mathrm{l})$ and reverse transcriptase $(1 \mu \mathrm{l})$ were added (all from Takara Biotechnology Co., Ltd., Dalian, China), followed by incubation at $50^{\circ} \mathrm{C}$ for $50 \mathrm{~min}$ in water bath. The synthesized cDNA was stored at $-20^{\circ} \mathrm{C}$.
The qPCR assays were performed on an ABI 7500 FAST Real-Time System (Applied Biosystems; Thermo Fisher Scientific, Inc.). The PCR reaction system contained cDNA (1 $\mu \mathrm{l}), 10 \mathrm{X}$ buffer $(2 \mu \mathrm{l}), \mathrm{MgCl}_{2}(1 \mu \mathrm{l})$, SYBR PrimeScript RT-PCR kit assay mix $(1 \mu \mathrm{l})$, double distilled $\mathrm{H}_{2} \mathrm{O}(14.8 \mu \mathrm{l})$ and Taq polymerase $(0.2 \mu \mathrm{l})$ (SYBR PrimeScript RT-PCR kit; Takara Biotechnology Co., Ltd.). PCR conditions were as follows: $95^{\circ} \mathrm{C}$ for $2 \mathrm{~min}$, followed by 40 cycles of $94^{\circ} \mathrm{C}$ for $20 \mathrm{sec}, 60^{\circ} \mathrm{C}$ for $20 \mathrm{sec}$ and $72^{\circ} \mathrm{C}$ for $30 \mathrm{sec}$, and a final elongation at $72^{\circ} \mathrm{C}$ for $10 \mathrm{~min}$. Primers were as follows: TLR4 forward, 5'-AAGCCGAAAGGTGATTGTTG-3' and reverse, 5'-CTGAGCAGGGTCTTCTCCAC-3'; $\beta$-actin (reference gene) forward, 5'-AGCGAGCATCCCCCAAAGTT-3' and reverse, 5'-GGGCACGAAGGCTCATCATT-3'. Quantitative evaluation was performed using the $\Delta \Delta \mathrm{Cq}$ method (4).

Western blot analysis. Tissues were lysed for $30 \mathrm{~min}$ prior to centrifugation at $1,204 \mathrm{x} \mathrm{g}$ and $4^{\circ} \mathrm{C}$ for $5 \mathrm{~min}$. The protein concentration in supernatant was determined using the bicinchoninic acid method using a BCA kit (Biotek China, Beijing, China). Total protein (10 $\mu \mathrm{g}$ per lane) was subjected to $10 \%$ SDS-PAGE at a constant $80 \mathrm{~V}$ for $30 \mathrm{~min}$ followed by $120 \mathrm{~V}$ until the markers (Takara Biotechnology Co., Ltd.) reached the edge of the gel. The samples were electrotransferred onto a polyvinylidene difluoride membrane (Takara Biotechnology Co., Ltd.) at constant $80 \mathrm{~V}$ at $4^{\circ} \mathrm{C}$ for $2 \mathrm{~h}$. The membrane was blocked with skimmed milk (1\%) for $1 \mathrm{~h}$ at room temperature. Mouse anti-human RAF, AKT, ERK, IкB- $\alpha$, p105/P50, RAS, P-AKT, FAK, MEK, p65 (1:1,000 dilution) and $\beta$-actin primary antibodies (1:5,000 dilution; Santa Cruz Biotechnology, Dallas, TX, USA) were added, followed by incubation with shaking overnight at $4^{\circ} \mathrm{C}$. After rinsing with PBS containing Tween-20 (3x10 min), the rabbit anti-mouse monoclonal secondary antibody $(1: 3,000$; Santa Cruz Biotechnology, Dallas, TX, USA) labeled with horseradish peroxidase was added prior to incubation at room temperature for $2 \mathrm{~h}$, followed by rinsing with PBS containing Tween 20 (3x10 min). The immunoreactive bands were visualized by enhanced chemiluminescence (ECL enhanced chemiluminescence kit; Takara Biotechnology Co., Ltd.).

Statistical analysis. All data were analyzed using SPSS 17.0 (SPSS, Inc., Chicago, IL, USA). Values are expressed as the mean \pm standard deviation. Analysis of variance was used for comparisons among multiple groups. Comparisons between samples were performed using Student's t-test. $\mathrm{P}<0.05$ was considered to indicate a statistically significant difference.

\section{Results}

AIDS-KS is mainly distributed in the face and limbs, while classic KS is mainly distributed in the limbs. To assess the distribution of KS tissues on the bodies of patients, the locations of KS tissues were determined. AIDS-KS tissues were mainly distributed in the face (9 cases, 34.6\%), upper limb (6 cases, 23.1\%), lower limbs ( 7 cases, 26.9\%), back ( 2 cases, $7.7 \%$ ) and oral mucosa (2 cases, 7.7\%). Classic KS tissues were mainly distributed in the limbs (7 cases, $77.8 \%$ ) and face ( 2 cases, $22.2 \%$ ). The results indicated that AIDS-KS is 
Table I. General data of included subjects.

\begin{tabular}{lcccc}
\hline Group & Cases $(\mathrm{n})$ & Males $n(\%)$ & Age (years) & CD4+ T-lymphocyte count $(\mathrm{n} / \mu \mathrm{l})$ \\
\hline AIDS-KS & 26 & $21(80.8)$ & $43.3 \pm 11.6$ & $197.5 \pm 80.9$ \\
Classical KS & 9 & $7(77.8)$ & $60.7 \pm 16.5$ & $663.0 \pm 137.9$ \\
Normal control & 10 & $6(60.0)$ & $45.9 \pm 15.1$ & $745.4 \pm 145.4$ \\
\hline
\end{tabular}

Values are expressed as the mean \pm standard deviation. AIDS, acquired immunodeficiency syndrome; KS, Kaposi's sarcoma.

A

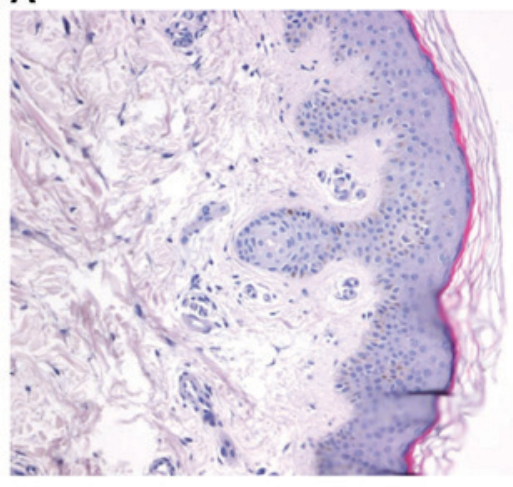

C

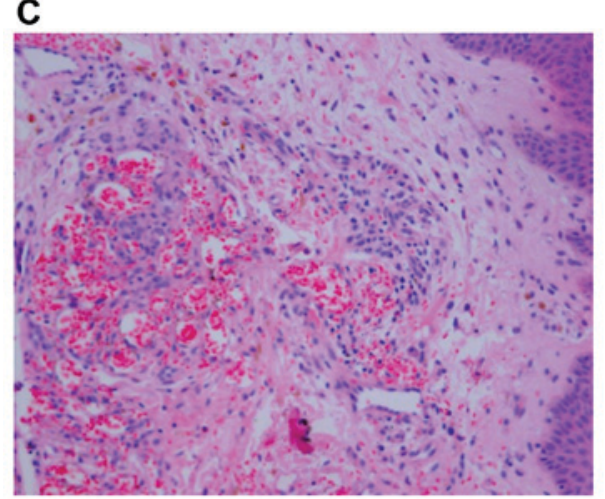

B

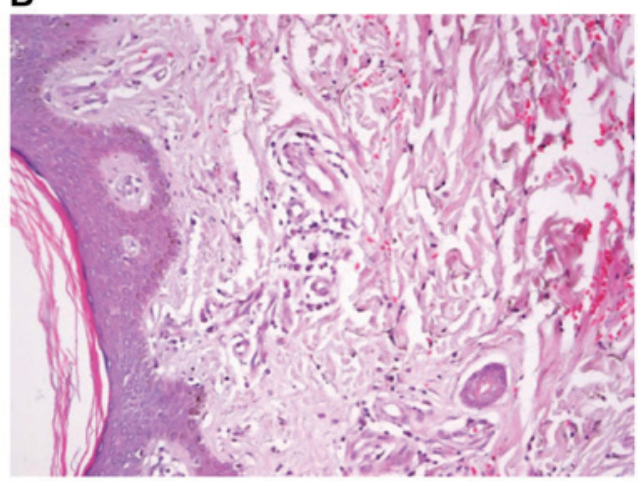

Figure 1. Histopathological changes in KS tissues. (A) Control tissue from healthy control tissue. Tumor tissue lesions of (B) AIDS-KS patients and (C) classic KS patients. The tissues were stained using hematoxylin and eosin (magnification, x200). KS, Kaposi's sarcoma; AIDS, acquired immunodeficiency syndrome.

mainly distributed in the face and limbs, while classic KS is mainly distributed in the limbs.

Histopathological characteristics of AIDS-KS and classic $K S$ tissues are different from those of normal tissues. To investigate the histopathology of KS tissues, hematoxylin and eosin staining was performed. Microscopy showed extravasation of red cells in the dermis, endothelial hyperplasia, tube obliteration, vascular labyrinth and vascular gap formation in AIDS-KS and classic KS tissues (Fig. 1A and B). In addition, large shuttle-type endothelial cells were observed in the vascular wall and undifferentiated abnormal cells with giant nuclei were observed around the blood vessels in AIDS-KS and classic KS tissues (Fig. 1C and D). These results suggested that the histopathological characteristics of AIDS-KS and classic KS tissues are different from those of normal tissues.

TLR4 is mainly distributed in the dermis of KS tissues. To visualize the distribution of TLR4 in KS tissues, immunohistochemical staining was used. TLR4-positive cells were observed in the dermis of KS tissues. TLR4 expression was mainly present in the cell membrane, cytoplasm and nuclei of endothelial cells and abnormal tumor cells, with the levels of expression being higher in the epidermis. The expression of TLR4 in gland ducts was also high. However, expression of TLR4 in skin tissues of normal subjects and AIDS patients was relatively low (Fig. 2). These results indicated that TLR4 is mainly distributed in the dermis of KS tissues.

TLR4 mRNA is downregulated in classic KS and AIDS-KS. To measure the expression of TLR4 mRNA in classic KS, AIDS-KS and normal tissues, agarose gel electrophoresis and RT-qPCR were performed. In the agarose gel, bands of $28 \mathrm{~S}$ and $18 \mathrm{~S}$ were clearly visualized, while no obvious $5 \mathrm{~S}$ band was observed (Fig. 3A). In addition, electrophoresis of PCR products of the TLR4 gene showed that target bands (112 bp) of AIDS-KS and classic KS were thinner than those of normal 
A

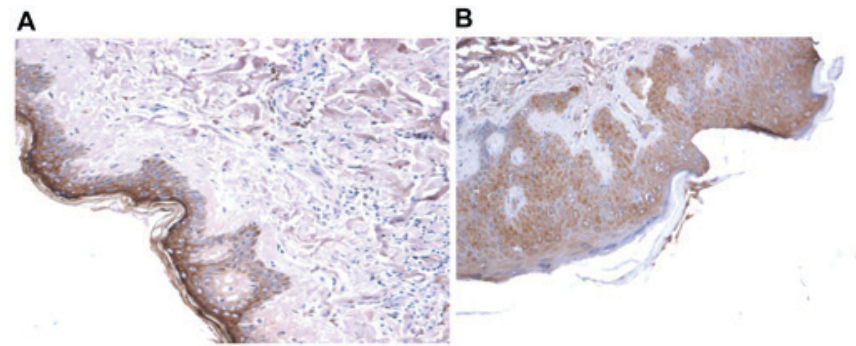

D
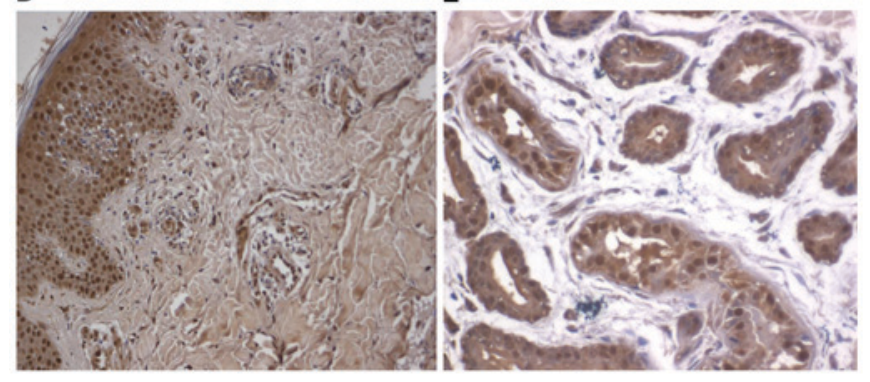

E

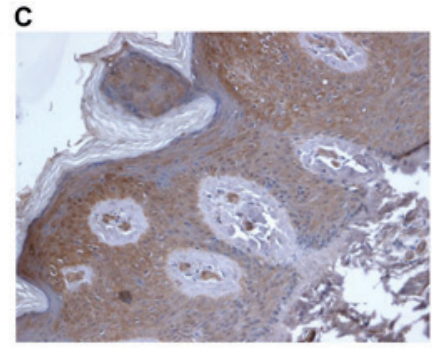

Figure 2. Localization of TLR4 expression. Immunohistochemical analysis of TLR4 expression in (A) healthy controls, (B) classic KS tissues, (C) AIDS-KS tissues, (D) dermis of AIDS-KS patients and (E) dermis of AIDS-KS patients (magnification, A-D: 200x; E: 400x). TLR4, Toll-like receptor 4.

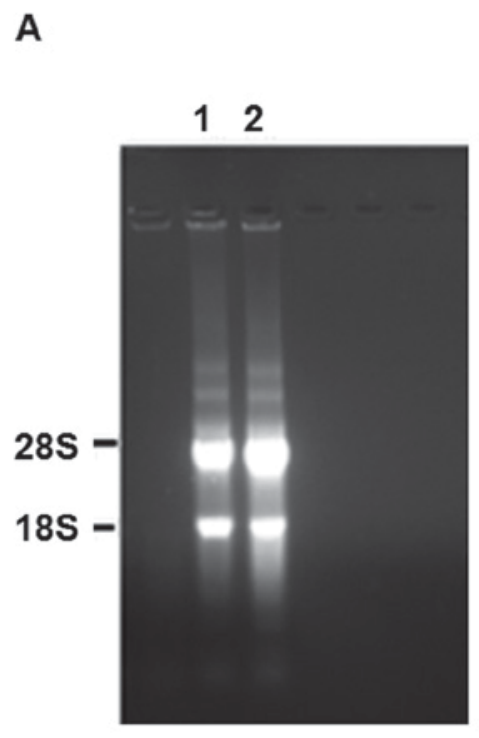

B
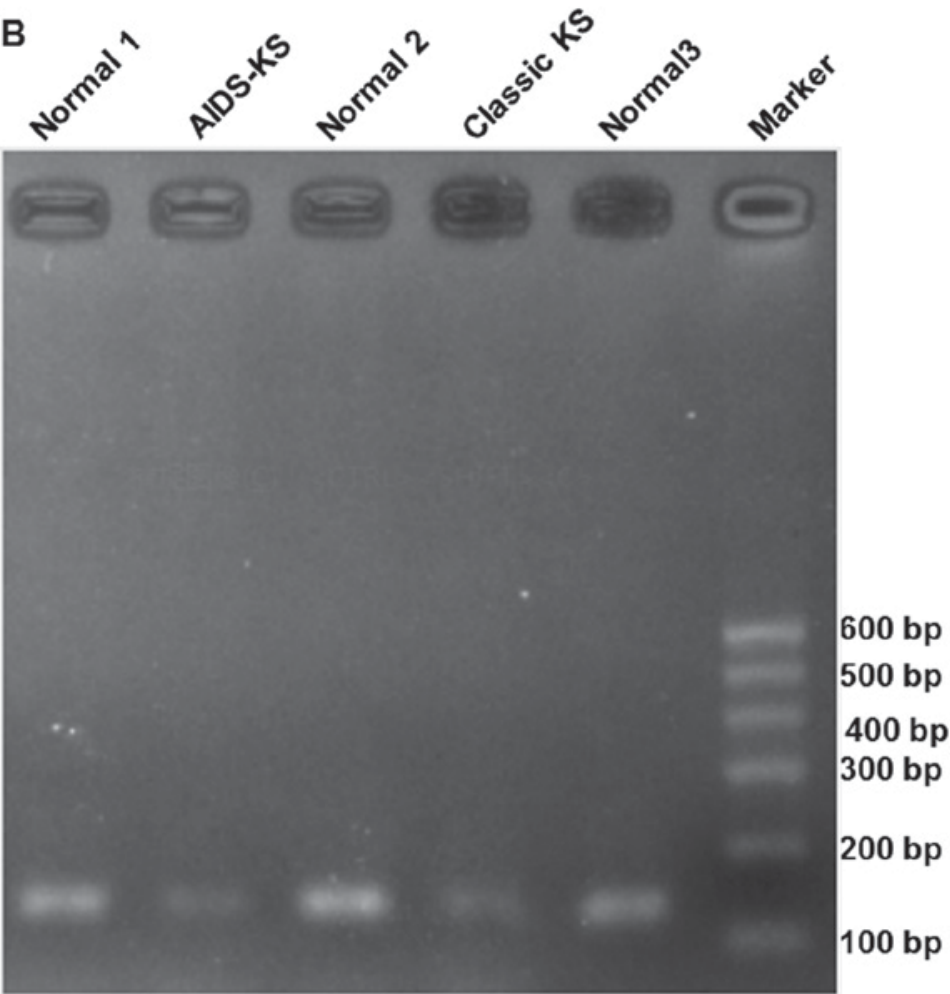

Figure 3. TLR4 mRNA integrity and PCR results. (A) Total RNA (28S and 18S). No obvious 5S was observed. Lane 1, AIDS-KS; lane 2, classic KS. (B) PCR products of TLR4 in different groups. TLR4, Toll-like receptor 4; PCR, polymerase chain reaction; KS, Kaposi's sarcoma; AIDS, acquired immunodeficiency syndrome.

tissues (Fig. 3B). RT-qPCR revealed that the expression of TLR4 mRNA in AIDS-KS tissues was significantly lower than that in normal tissues $(\mathrm{t}=3.368, \mathrm{P}=0.0017)$. Similarly, the level of TLR4 mRNA in classic KS tissues was significantly lower than that in normal tissues $(\mathrm{t}=2.076, \mathrm{P}=0.0497)$. However, the expression of TLR4 mRNA in classic KS was not significantly different from that in AIDS-KS ( $\mathrm{t}=1.230, \mathrm{P}=0.46$; Fig. 4).
These results suggested that TLR4 mRNA expression levels were reduced in classic KS and AIDS-KS.

$R A S, R A F, E R K, p-A K T, I \kappa B-\alpha, P 50$ and $P 65$ as proteins of the TLR4 signaling pathway in AIDS-KS and KS tissues are higher than those in normal tissues. To determine the expression of proteins involved in the TLR4 signaling 


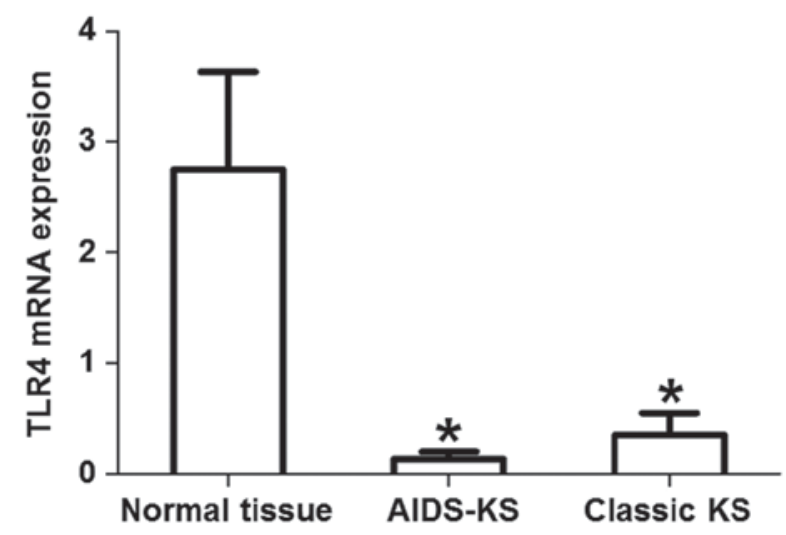

Figure 4. TLR4 mRNA expression in normal, AIDS-KS and classic KS tissues determined using reverse-transcription quantitative polymerase chain reaction. "P<0.05 vs. normal tissue. TLR4, Toll-like receptor 4; KS, Kaposi's sarcoma; AIDS, acquired immunodeficiency syndrome.

pathway, western blot analysis was used. The results demonstrated that the protein expression levels of RAS, RAF, ERK (P40 and P42), inhibitor of nuclear factor (NF)- $\kappa \mathrm{B}(\mathrm{I} \kappa \mathrm{B})-\alpha$, $\mathrm{P} 50$ and $\mathrm{P} 65$ in classic KS tissues were significantly higher than those in normal tissues $(\mathrm{P}<0.05$; Fig. 5 and Table II). Protein levels of RAS in AIDS-KS tissue were significantly higher than that of normal tissues $(\mathrm{P}<0.05)$. Furthermore, ERK protein expression (P40 and P42), P50 and P65 in classic KS tissues were significantly higher than those in AIDS-KS tissues $(\mathrm{P}<0.05)$. These results indicated that the expressions of RAS, RAF, ERK (P40 and P42), IкB- $\alpha$, P50 and P65 proteins of TLR4 signaling pathways in AIDS-KS and KS tissues was upregulated compared to normal tissues. Additionally, results revealed significant differences in ERK (P40 and P42), P50 and P65 protein levels between AIDS-KS and classic KS tissues.

\section{Discussion}

KS may be clinically divided into four types: i) Classic KS, ii) African KS, iii) AIDS-KS and iv) immunosuppressionassociated KS (5). KS is an opportunistic tumor type in patients with advanced AIDS (6). Human herpesvirus-8 (HHV-8) represents the etiological basis of KS to cause KSHV (7). HHV-8 is detected in nearly all KS tissues (8). If HHV-8 is detected in AIDS patients, it is very likely that the patient will develop KS within 4 years (9). The present study found that AIDS-KS was distributed primarily in the face. However, classic KS was mainly distributed in the limbs. In addition, Uygur males accounted for the majority of patients with KS. A large amount of TLR4-positive cells were observed in the dermis of AIDS-KS patients, indicating that TLR4 expression is associated with the occurrence and development of AIDS-KS. However, in the present study, TLR4 expression was not measured at different time-points of tumor growth in AIDS-KS patients. Therefore, the association between TLR4 expression and AIDS-KS growth remains elusive. At the early stage of AIDS-KS, TLR4 may possibly aid in the resistance to HHV-8 infection and propagation, but may promote the growth of KS as the disease develops (10-13). Consistently, low TLR4 expression was also observed in the dermis of classic KS
Table II. Expression of proteins involved in Toll-like receptor 4 signaling pathway.

\begin{tabular}{lccc}
\hline Proteins & Normal tissues & $\begin{array}{c}\text { Classic Kaposi's } \\
\text { sarcoma tissues }\end{array}$ & $\begin{array}{c}\text { AIDS Kaposi's } \\
\text { sarcoma tissues }\end{array}$ \\
\hline RAF & $0.54 \pm 0.08$ & $1.69 \pm 0.96^{\mathrm{a}}$ & $0.95 \pm 0.57$ \\
RAS & $0.69 \pm 0.13$ & $1.32 \pm 0.12^{\mathrm{a}}$ & $1.30 \pm 0.41^{\mathrm{a}}$ \\
AKT & $1.12 \pm 0.10$ & $1.27 \pm 0.24$ & $1.17 \pm 0.20$ \\
P-AKT & $1.54 \pm 0.27$ & $2.33 \pm 1.03$ & $1.73 \pm 0.55$ \\
P40 & $0.65 \pm 0.06$ & $1.48 \pm 0.49$ & $0.94 \pm 0.42^{\mathrm{b}}$ \\
P42 & $0.79 \pm 0.10$ & $1.13 \pm 0.50$ & $0.87 \pm 0.30^{\mathrm{b}}$ \\
FAK & $1.06 \pm 0.08$ & $1.35 \pm 0.46$ & $1.17 \pm 0.32$ \\
IאB- $\alpha$ & $1.28 \pm 0.14$ & $2.07 \pm 0.66^{\mathrm{a}}$ & $1.61 \pm 0.50$ \\
MEK & $1.71 \pm 0.18$ & $1.81 \pm 0.41$ & $2.09 \pm 0.54$ \\
P105 & $1.32 \pm 0.12$ & $1.75 \pm 0.67$ & $1.27 \pm 0.42$ \\
P50 & $1.21 \pm 0.06$ & $2.03 \pm 0.58$ & $1.53 \pm 0.43^{\mathrm{b}}$ \\
P65 & $1.31 \pm 0.18$ & $1.82 \pm 0.50$ & $1.62 \pm 0.47^{\mathrm{b}}$ \\
\hline
\end{tabular}

Values are expressed as the mean \pm standard deviation. ERK, extracellular signal-regulated kinase; p-AKT, phosphorylated AKT; IкB- $\alpha$, inhibitor of nuclear factor- $\kappa \mathrm{B}-\alpha$; MEK, mitogen-associated protein kinase/ERK kinase; FAK, focal adhesion kinase. ${ }^{\mathrm{a}} \mathrm{P}<0.05$ vs. normal tissues; ${ }^{\mathrm{P}}<0.05$ vs. Classic Kaposi's sarcoma tissues.

tissues, suggesting that TLR4 participates in the occurrence of AIDS-KS as well as classic KS. A previous study showed that the infection rate of HHV-8 is high in classic KS of Xinjiang Autonomous Region (14). HHV-8 is the common cause of AIDS-KS and classic KS, explaining the similarity of TLR4 expression in the two types of KS.

Consistent with the study by Lagos et al (15), the present study showed that TLR4 mRNA expression was significantly downregulated in classic KS and AIDS-KS, suggesting that HHV-8 inhibits inflammatory pathways after infection. Zhou et al (16) reported that TLR4 expression in peripheral blood is upregulated in AIDS patients and that TLR4 mRNA expression in peripheral blood mononuclear cells in untreated AIDS patients is significantly increased. After using highly active anti-retroviral therapy to inhibit the virus, the expression of TLRs was reduced to a normal level, suggesting that human immunodeficiency virus (HIV) directly affects the expression of TLRs and the function of immune cells (17). Bosinger et al (18) reported that the expression of TLR4 in the peripheral blood of Rhesus monkeys with acute 89.6P (HIV) infection is reduced. In the acute phase of HIV infection, TLR4 is downregulated. However, TLR4 expression is upregulated during the development of AIDS, in which opportunistic infections induce local or systemic inflammatory responses. KS occurs in the AIDS phase of HIV infection, mainly on the back, prothorax, limbs, oral cavity and nose $(19,20)$. The pathology of AIDS-KS is similar to that of classic KS, being characterized by abnormal angiogenesis and spindle cell proliferation (21).

In the present study, expression of RAS, RAF, ERK (P40/P42), IкB- $\alpha$, P50 and P65 protein in classic KS was significantly higher than that in normal tissues. Furthermore, RAS levels were significantly higher in AIDS-KS tissues when 


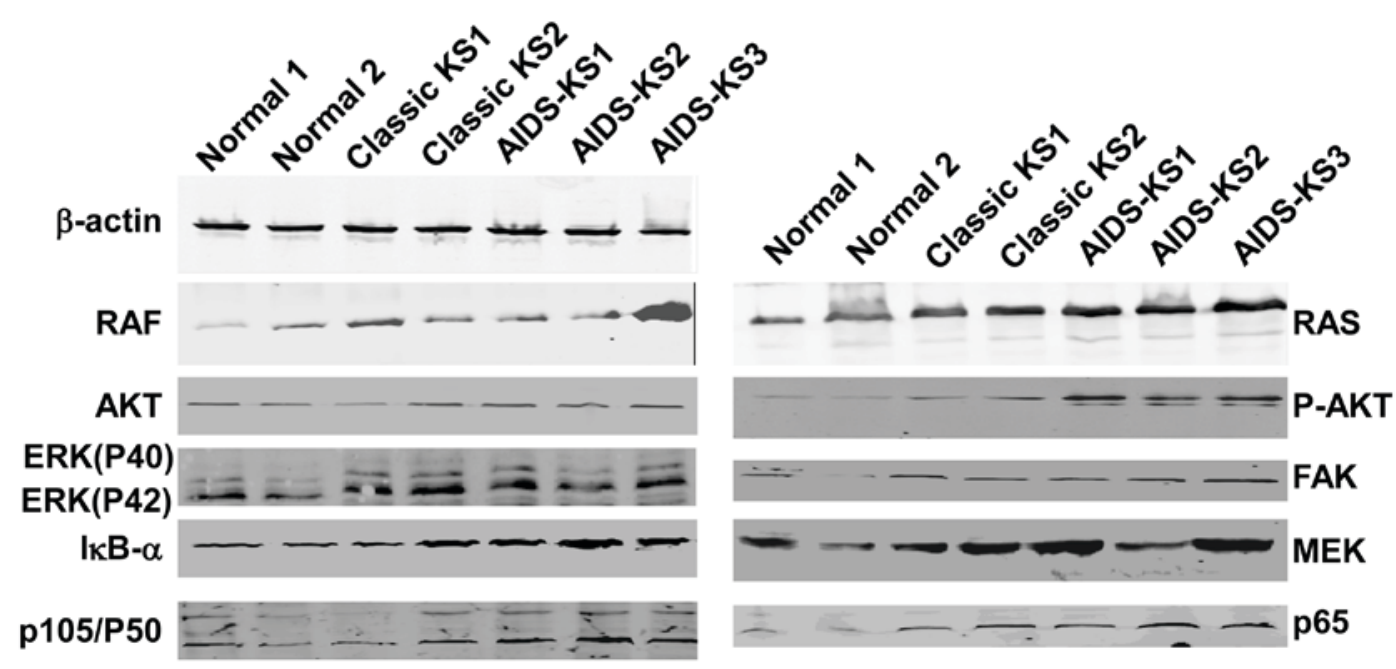

Figure 5. Expression of proteins associated with the toll-like receptor 4 signaling pathway. Western blot analysis was used to detect protein expression. ERK,

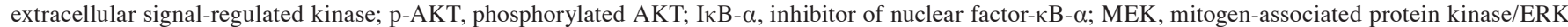
kinase; FAK, focal adhesion kinase.

compared with normal tissues. The levels of ERK (P40/P42), P50 and P65 protein were also significantly different between AIDS-KS and classic KS. The expression of other proteins involved in TLR4 signaling pathways in KS tissues was not significantly different from that in normal tissues. RAS, RAF, ERK, focal adhesion kinase (FAK) and mitogen-associated protein kinase/ERK kinase (MEK) proteins exist in the cytoplasm (22). Ras protein is the upstream protein of the RAF/MEK/ERK pathway, which may be activated by the secretion of numerous stimulating factors (23). After the activation of RAS protein, it binds to the RAF-1 domain to activate RAF, which subsequently activates MEK. Activation of ERKs by MEK stimulates phosphorylation of downstream substrates (24). ERKs are downstream proteins of multiple growth factors, regulating the cell proliferation, differentiation and survival, as well as gene expression. Overexpression of ERK is found in numerous human cancer types (25). In the present study, expression of RAS, RAF and ERK in KS tissues was higher than that in normal tissues, possibly due to HHV-8 infection. AKT has important roles in cell survival and apoptosis (26). The present study determined that the expression of ERK (P40/P42), P50 and P65 in AIDS-KS was lower than that in classic KS. FAK is important in tumor progression. Inhibition of FAK expression or activity suppresses cell proliferation and promotes apoptosis (27). In the present study, FAK expression in KS tissues was not significantly different from that in normal tissues. This may be due to the limited number of patients. NF- $\mathrm{KB}$ is a dimer of p50 and p65 and the activation of NF- $\mathrm{kB}$ promotes tumor growth (28). The expression of P50 and P65 in KS was higher than that in normal tissues. HHV-8 infection activates ERK and its downstream signaling pathway, enhances NF- $\kappa \mathrm{B}$ expression and regulates the expression of tumor genes (29). IкB- $\alpha$ binds to the P50 and P65 dimer and prevents the binding of the dimer with nuclear DNA. When the classic pathway is activated, the dimer is released and activated, and NF- $\mathrm{KB}$ then enters the nucleus (30).

The expression of TLR4 mRNA in KS tissues of AIDS-KS patients was lower compared with that in normal tissues, while the expression of RAS, RAF, ERK, IкB- $\alpha$, P50 and P65 in AIDS-KS tissues was higher than that in normal tissues. This may be due to the following mechanism. HHV-8 encodes G protein-coupled receptors (vGPCR) and IFN regulatory factor-1 (vIRF1), and partially inhibits the expression of TLR4 (31). HHV-8 structural protein and vGPCR activates ERK, and phosphorylated ERK acts on the conserved ETS binding site on the TLR4 promoter, reducing TLR4 mRNA levels and TLR4 expression (32). vIRF1 blocks IFN mediated by TLR. Each vIRF1 has its unique function and mechanism that inhibits anti-viral responses of IFN (33). Increase of HHV-8-TIR-domain-containing adapter-inducing IFN- $\beta$ (TRIF) inhibits the TLR-TRIF signaling pathway and downregulates TLR4 (34). Prior to the occurrence of tumors, the sustained activation of the TLR4 signaling pathway indicates the existence of chronic inflammation. Studies have indicated that sustained chronic inflammation is the key driver of malignant tumor development $(11,35)$. Another study showed that TLR4 expression is high in lung, laryngeal and colon cancer, and activation of the TLR4 signaling pathway is important in specific anti-tumor immunity (36). Combined with previous studies, the results demonstrate that the expression of TLR4 and its associated signaling pathway proteins do not differ between AIDS-KS and classic KS.

In conclusion, the present study demonstrated the close association between TLR4 and AIDS-KS. In AIDS-KS, TLR4 mRNA levels were downregulated. Interactions between HHV-8 and ERK may have induced the high expression of proteins of the TLR4 signaling pathway in AIDS-KS tissues. As TLR4 is downregulated in AIDS-KS and classic KS, its restoration may inhibit the occurrence or growth of KS as a novel therapeutic strategy. However, the effect of TLR4 overexpression was not assessed in the present study. Future studies should thus be performed to examine this.

\section{Acknowledgements}

Not applicable. 


\section{Funding}

The present study was supported by the National Natural Science Foundation of China (grant nos. 81060131 and 81260246).

\section{Availability of data and materials}

The analyzed data sets generated during the present study are available from the corresponding author on reasonable request.

\section{Authors' contributions}

XLu collected data from subjects, performed H\&E staining, immunohistochemistry, RT-qPCR, western blotting and statistical analysis, and wrote the manuscript; XW and $\mathrm{XLi}$ participated in $\mathrm{H} \& \mathrm{E}$ staining and immunohistochemistry; KP and YZ also performed RT-qPCR and western blotting; and $\mathrm{WM}$ conceived and designed the present study and revised the manuscript. All authors have read and approved this manuscript.

\section{Ethics approval and consent to participate}

All procedures were approved by the Ethics Committee of Xinjiang Medical University (Xinjiang, China) and written informed consent was obtained from all patients or their families.

\section{Patient consent for publication}

Not applicable.

\section{Competing interests}

All authors have no conflict of interest to declare.

\section{References}

1. Cancian L, Hansen A and Boshoff C: Cellular origin of Kaposi's sarcoma and Kaposi's sarcoma-associated herpesvirus-induced cell reprogramming. Trends Cell Biol 23: 421-432, 2013.

2. Wang X, Zhang Z, Liu T, Li X, Zhang Q, Wang L, Lu X, Lin R and Wen H: Analysis of infection rate of human herpes virus 8 in blood donors in Xinjiang Autonomous Region. Chin J Infect Dis 27: 502-504, 2009 (In Chinese).

3. Lester SN and Li K: Toll-like receptors in antiviral innate immunity. J Mol Biol 426: 1246-1264, 2014.

4. Livak KJ and Schmittgen TD: Analysis of relative gene expression data using real-time quantitative PCR and the 2(-Delta Delta C(T)) method. Methods 25: 402-408, 2001.

5. Laresche C, Fournier E, Dupond AS, Woronoff AS, Drobacheff-Thiebaut C, Humbert P and Aubin F: Kaposi's sarcoma: A population-based cancer registry descriptive study of 57 consecutive cases diagnosed between 1977 and 2009. Int J Dermatol 53: e549-e554, 2014.

6. Alcendor DJ: KSHV Down-regulates Tropoelastin in Both an in-vitro and in-vivo Kaposi's Sarcoma Model. J Oncobiomarkers 2: 1-7, 2015.

7. Machado PR, Farias KJ, Pereira MG, Freitas PP and Fonseca BA: Human herpesvirus 8 (HHV-8) detected by nested polymerase chain reaction (PCR) in HIV patients with or without Kaposi's sarcoma. An analytic cross-sectional study. Sao Paulo Med J 134: 187-192, 2015.

8. Fernandes F, Eloy C, Carimo A, Pinto P, Graves S, Simões J, Carrilho C and Lopes JM: Simultaneous presentation of Kaposi sarcoma and HHV8-associated large B-cell lymphoma in the same lymph node: A rare diagnosis in an HIV-negative patient. Am J Case Rep 14: 263-266, 2013.
9. Boivin G, Côté S, Cloutier N, Abed Y, Maguigad M and Routy JP: Quantification of human herpesvirus 8 by real-time PCR in blood fractions of AIDS patients with Kaposi's sarcoma and multicentric Castleman's disease. J Med Virol 68: 399-403, 2002.

10. Wang HW, Trotter MW, Lagos D, Bourboulia D, Henderson S, Mäkinen T, Elliman S, Flanagan AM, Alitalo K and Boshoff C: Kaposi sarcoma herpesvirus-induced cellular reprogramming contributes to the lymphatic endothelial gene expression in Kaposi sarcoma. Nat Genet 36: 687-693, 2004.

11. Bauer AK, Dixon D, DeGraff LM, Cho HY, Walker CR, Malkinson AM and Kleeberger SR: Toll-like receptor 4 in butylated hydroxytoluene-induced mouse pulmonary inflammation and tumorigenesis. J Natl Cancer Inst 97: 1778-1781, 2005.

12. Zhang $\mathrm{K}$, Zhou B, Wang Y, Rao L and Zhang L: The TLR4 gene polymorphisms and susceptibility to cancer: A systematic review and meta-analysis. Eur J Cancer 49: 946-954, 2013.

13. Medzhitov R, Preston-Hurlburt P and Janeway CA Jr: A human homologue of the Drosophila Toll protein signals activation of adaptive immunity. Nature 388: 394-397, 1997.

14. Li D, Yang L, Tan XH, Li F, Qin J, Guo S, Pu X and Xie J: Detection of HHV-8 DNA in Serum of 29 Xinjiang Classic Kaposi Sarcoma by Nested PCR. Chin J Dermatovenereol 19: 329-220, 2005 (In Chinese).

15. Lagos D, Vart RJ, Gratrix F, Westrop SJ, Emuss V, Wong PP, Robey R, Imami N, Bower M, Gotch F and Boshoff C: Toll-like receptor 4 mediates innate immunity to Kaposi sarcoma herpesvirus. Cell Host Microbe 4: 470-483, 2008.

16. Zhou L, Shang H, Wang Y, Li G, Ding H, Zhang X, Dai D and Shi W: The expression of TLR4 on peripheral blood monocyte and TNF- $\alpha$ concentration of plasma in Chinese HIV/AIDS patients. Chin J Microbiol Immunol 27: 1016-1019, 2007 (In Chinese).

17. Lester RT, Yao XD, Ball TB, McKinnon LR, Kaul R, Wachihi C, Jaoko W, Plummer FA and Rosenthal KL: Toll-like receptor expression and responsiveness are increased in viraemic HIV-1 infection. AIDS 22: 685-694, 2008.

18. Bosinger SE, Hosiawa KA, Cameron MJ, Persad D, Ran L, Xu L, Boulassel MR, Parenteau M, Fournier J, Rud EW and Kelvin DJ: Gene expression profiling of host response in models of acute HIV infection. J Immunol 173: 6858-6863, 2004.

19. Speicher DJ, Sehu MM, Johnson NW and Shaw DR: Successful treatment of an HIV-positive patient with unmasking Kaposi's sarcoma immune reconstitution inflammatory syndrome. J Clin Virol 57: 282-285, 2013.

20. Tamburro KM, Yang D, Poisson J, Fedoriw Y, Roy D, Lucas A, Sin SH, Malouf N, Moylan V, Damania B, et al: Vironome of Kaposi sarcoma associated herpesvirus-inflammatory cytokine syndrome in an AIDS patient reveals co-infection of human herpesvirus 8 and human herpesvirus 6A. Virology 433: 220-225, 2012.

21. Maimaitiaili W, Pan K, Lu X, Sun X, Yibaguli A, Yang K, Zuohela T, Adili K and Zhang Y: Clinical, pathological and prognosis analyses of AIDS patients with Kaposi sarcoma. Chin J Infect Dis 30: 368-370, 2012 (In Chinese).

22. Rea K, Sensi M, Anichini A, Canevari S and Tomassetti A: EGFR/MEK/ERK/CDK5-dependent integrin-independent FAK phosphorylated on serine 732 contributes to microtubule depolymerization and mitosis in tumor cells. Cell Death Dis 4: e815, 2013.

23. Buscà R, Christen R, Lovern M, Clifford AM, Yue JX, Goss GG, Pouysségur $\mathrm{J}$ and Lenormand P: ERK1 and ERK2 present functional redundancy in tetrapods despite higher evolution rate of ERK1. BMC Evol Biol 15: 179, 2015.

24. Singh A, Ruan Y, Tippett T and Narendran A: Targeted inhibition of MEK 1 by cobimetinib leads to differentiation and apoptosis in neuroblastoma cells. J Exp Clin Cancer Res 34: 104, 2015.

25. Tamminen JA, Yin M, Rönty M, Sutinen E, Pasternack A, Ritvos O, Myllärniemi $\mathrm{M}$ and Koli $\mathrm{K}$ : Overexpression of activin-A and -B in malignant mesothelioma-attenuated Smad3 signaling responses and ERK activation promote cell migration and invasive growth. Exp Cell Res 332: 102-115, 2015.

26. Park HS, You GE, Yang KH, Kim JY, An S, Song JY, Lee SJ, Lim YK and Nam SY: Role of AKT and ERK pathways in controlling sensitivity to ionizing radiation and adaptive response induced by low-dose radiation in human immune cells. Eur J Cell Biol 9: 653-660, 2015.

27. Nguyen MP, Lee D, Lee SH, Lee HE, Lee HY and Lee YM: Deguelin inhibits vasculogenic function of endothelial progenitor cells in tumor progression and metastasis via suppression of focal adhesion. Oncotarget 6: 16588-16600, 2015. 
28. Shostak $\mathrm{K}$ and Chariot A: EGFR and NF- $\kappa \mathrm{B}$ : Partners in cancer. Trends Mol Med 21: 385-393, 2015.

29. Cannon M, Philpott NJ and Cesarman E: The Kaposi's sarcoma-associated herpesvirus $\mathrm{G}$ protein-coupled receptor has broad signaling effects in primary effusion lymphoma cells. J Virol 77: 57-67, 2003.

30. Pati S, Cavrois M, Guo HG, Foulke JS Jr, Kim J, Feldman RA and Reitz M: Activation of NF-kappaB by the human herpesvirus 8 chemokine receptor ORF74: evidence for a paracrine model of Kaposi's sarcoma pathogenesis. J Virol 75: 8660-8673, 2001.

31. Gregory SM, West JA, Dillon PJ, Hilscher C, Dittmer DP and Damania B: Toll-like receptor signaling controls reactivation of KSHV from latency. Proc Natl Acad Sci USA 106: 11725-11730, 2009.

32. Hävemeier A, Gramolelli S, Pietrek M, Jochmann R, Stürzl M and Schulz TF: Activation of NF- $\kappa$ B by the Kaposi's sarcoma-associated herpesvirus K15 protein involves recruitment of the NF- $\kappa B$ -inducing kinase, $\mathrm{I} \kappa \mathrm{B}$ kinases, and phosphorylation of $\mathrm{p} 65$ J Virol 88: 13161-13172, 2014.

33. Jacobs SR, Gregory SM, West JA, Wollish AC, Bennett CL, Blackbourn DJ, Heise MT and Damania B: The viral interferon regulatory factors of kaposi's sarcoma-associated herpesvirus differ in their inhibition of interferon activation mediated by toll-like receptor 3. J Virol 87: 798-806, 2013.
34. Meyer F, Ehlers E, Steadman A, Waterbury T, Cao M and Zhang L: TLR-TRIF pathway enhances the expression of KSHV replication and transcription activator. J Biol Chem 288: 20435-20442, 2013.

35. Ahmad H, Gubbels R, Ehlers E, Meyer F, Waterbury T, Lin $\mathrm{R}$ and Zhang L: Kaposi sarcoma-associated herpesvirus degrades cellular Toll-interleukin-1 receptor domain-containing adaptor-inducing beta-interferon (TRIF). J Biol Chem 286: 7865-7872, 2011.

36. Guo Y, Li Y, Wei X, Feng Z and Yang S: Expression of TLR2 and TLR4 in primary liver cancer. Chin J Pathophysiol 24: 1912-1915, 2008 (In Chinese).

This work is licensed under a Creative Commons

Attribution-NonCommercial-NoDerivatives 4.0 International (CC BY-NC-ND 4.0) License. 